\title{
Effect of Occupational Environment on Male Infertility
}

\section{IJCRR}

Section: Healthcare

Sci. Journal Impact

Factor: $6.1(2018)$

ICV: 90.90 (2018)

(c) (i) (8)

Copyright@IJCRR

\section{Akshay Vinod Tayawade ${ }^{1}$, Aakash More ${ }^{2}$, Mehul Salve ${ }^{3}$, Deepti Shrivastava ${ }^{4}$}

PG, M.Sc. Clinical Embryology, Department of Anatomy, Jawaharlal Nehru Medical College, Datta Meghe Institute of Medical Sciences, Wardha, Maharashtra, India; ${ }^{2}$ Senior Embryologist Wardha Test Tube Baby Centre A.V.B.R.H, Jawaharlal Nehru Medical College, Datta Meghe Institute of Medical Sciences, Wardha; ${ }^{3}$ Associate Professor, Department of OBGY, Jawaharlal Nehru Medical College Datta Meghe Institute of

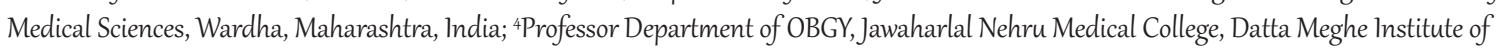
Medical Sciences, Wardha, Maharashtra, India.

\section{ABSTRACT}

Background: The impact of the environment on Male Infertility has shown the effect on, mood disorders, cancers at the genital region, declination in sperm concentration and multiple alterations in sexual behaviour. In the case of male infertility in the Indian population, some studies have also concluded that a specific mutation on MTHFR (Methylen etetrahydrofolate_Reductase) at C677T site is quite briefly associated with the male infertility problem. Similarly, in males; increased susceptibility to various complex disorders have been reported for the same type of mutation.

Objectives: To correlate MTHFR gene polymorphism and occupational environmental factors with defects in morphology, count and motility of sperm by normal sperm.

Methodology: Details of the occupational environment of the individual patient before Semen analysis. The semen analysis will be performed according to the WHO Guidelines 2010. Blood samples will be collected from patients matching the inclusion criteria, then Cryopreserving of sediments of blood samples will be done if required. Extraction of genomic DNA from blood Genotyping of MTFR gene PCR-RFLP method Identification of genotype by Electrophoresis and then Statistical analysis will be done for checking occ. Environmental factor effect with MTHFR gene polymorphism Comparison of epigenome between defected sperm and healthy sperm.

Expected Results: Three variable groups (Heat; Telecommunication radiation and chemical) will be formed concerning the exposure of environmental occupation on fertility perspective. Eventually, the severity of epigenetic cause for male infertility is expected to see in participants with \pm 15 years the exposure of any one or a combination of the variables of occupational environment.

Key Words: Male infertility, Occupational Environmental, Epigenetic

\section{INTRODUCTION}

Infertility specifically can be explained in terms of; ineptitude of a couple to reify pregnancy after being non-contraceptional sexually active for about one year. More often than not, infertility can be classified in two groups; primary (67-71\%): when the occurrence of clinical pregnancy has never reported; secondary (29-33\%): where there has been a pregnancy, regardless of the outcome. It affects 13-18\% of couples of reproductive age worldwide and is treatable in many cases. ${ }^{1}$ Both male and female contribute to the factors influencing infertility. In recent years, it was studied that; because of spermatogenic failure approximately $50 \%$ of in- fertility cases are associated with male factor, study shows a data in which about $30 \%$ are referred to as idiopathic infertility as overall $\sim 70 \%$ of the underlying etiological causes are known. ${ }^{2}$ Environment (Occupational, Physiological, Geographical) of an individual may lead to exposure to radiation, heat, heavy metals, chemicals can affect fertility in male. ${ }^{3}$ Research has also shown that genetic factors have a significant contribution to male infertility ${ }^{4}$; one of them is epigenetics. A prevalent functional definition of epigenetics can be stated as study of heritable changes in genome function that occur without a change in the DNA sequence. ${ }^{5}$ The regulation of gene expression (turning genes $\mathrm{ON}$ and $\mathrm{OFF}$, for instance) and in the maintenance of chromatin structure

\section{Corresponding Author:}

Aakash M More, Senior Embryologist Wardha Test Tube Baby Centre A.V.B.R.H, Jawaharlal Nehru Medical College, Datta Meghe Institute of Medical Sciences, Wardha, Maharashtra, India; Mob : 7756834128; Email: akshay.tayawade19@gmail.com

ISSN: 2231-2196 (Print)

Received: 16.09 .2020
ISSN: $0975-5241$ (Online)

Revised: 19.10 .2020
Accepted: 09.11 .2020
Published: 30.11 .2020 
and stability are some important aspects which are carried out three main epigenetic mechanisms ${ }^{6}$,

A. Methylation on DNA.

B. Post-translational phase modifications of histone

C. Noncoding RNAs.

Male infertility is a disorder of multiple factors diversely ranging from the environment to genetics which affects the spermatogenesis process. It is strictly controlled by a series of gene expression events. ${ }^{7}$ The process of spermatogenesis at variant stages and abnormal expression of the gene responsible to infertility in the male are both regulated by autosomal and Y-chromosomal genes both regulates. ${ }^{7}$ Research has shown that in the Indian population, a risk factor of idiopathic male infertility is due to homozygosity for C677T mutation in the MTHFR gene. ${ }^{8}$ The regulatory enzyme Methylenetetrahydrofolate reductase (MTHFR) is one which is involved in the metabolism of folate, DNA replication, and DNA and protein methylation. In the spermatogenesis process, a precursor of S-adenosylmethionine that functions as methyl donor for DNA and amino acid methylation are MTHFR. ${ }^{9}$ In this study, we will compare the effect of occupational environment on MTHRF gene polymorphism of male patients facing infertility factors visiting Wardha Test Tube Baby Centre. This comparison will be done with control who had a healthy baby without any infertility treatment.

In many studies, it has been mentioned about several factors that contribute to the causes of increased male infertility potentials. Widely it includes agents which are being used in agriculture and other small- and large-scale industry such as heavy metals and various chemical. However, other corporeal and biological elements like escalated contagion of Phyto/Xeno estrogen in the environment; over the revelation of radiation; global temperature; could cause harm and may affect male reproductive function. These effects have shown result in mood disorders, cancers at the genital region, declination in sperm concentration and multiple alterations in sexual behaviour. ${ }^{3}$ Parallelly, some studies also state that; in less than $50 \%$ of cases study the causes for infertility in males are mean to be known, out of which the major factors are; specific abnormalities in the Y chromosome; genetic or inherited disease. Deletion of the Y chromosome in gradually observed in about $10-20 \%$ of males having no sperms in the ejaculate. In this deleted region, located in Yq11 region, the Azoospermia Factor (AZF) locus is included. From this study, it was clear that; with a particular testicular histology an association of specific regulatory regions and several candidate genes have been found within these region. ${ }^{4}$

Certain studies also state that a specific mutation on MTHFR (Methylenetetrahydrofolate Reductase) at C677T site is quite briefly associated with the male infertility problem. Similarly, in this study, it was stated that in males; increased susceptibility to various complex disorders has been reported for the same type of mutation. Assessment of single nucleotide polymorphism (SNP) was done as a risk factor for idiopathic male infertility; for which on Indian population a case-control study was done on 11 samples. From about 151 cases of idiopathic oligozoospermia; azoospermia; nonobstruction, and 200 fertile males as controls, DNA samples were extracted and amplified using site-specific primers using PCR, and the mutation of Hinf-I-digestion was being analyzed. Notably, among infertile patients an escalated frequency of CT heterozygotes $(p<0.04)$ was stated as the main result. In the Indian population, a specific mutation on C677T site of MTHFR gene is audibly a risk factor for male infertility as it was recorded that $\mathrm{T}$ homozygotes in the control population were absent, in the control population of the study occurrence of $\mathrm{T}$ allele was eloquently low; as $\mathrm{T}$ homozygous were remarkably reported to be only six of 151 infertile cases. ${ }^{8}$

\section{OBJECTIVES}

Comparative study of the occupational environment and its effect on the genome for influencing infertility in the male may lead to understanding unknown idiopathic aspects of male infertility.

1. To study occupational environmental factors affecting male infertility in Vidarbha region.

2. To check methylation status for MTHFR gene polymorphism in male having infertility factor.

3. To correlate MTHFR gene polymorphism and occupational environmental factors with defects in morphology, count and motility of sperm by normal sperm.

4. To study idiopathic factors for male infertility

\section{MATERIALS AND METHODS}

\section{Study Design:}

Subject: Male partner of Infertile couple attending WARDHA TEST TUBE BABY CENTRE, AVBRH, Sawangi Meghe, Wardha.

INTERVENTION: Identification of genetic defects in infertile male partner and it's the correlation with corresponding Occupational environment.

COMPARISON: MTHFR gene polymorphism and corresponding occupational environmental factors will be compared with patients facing male infertility and normal (healthy) sample.

OUTCOME: Outcome will be seen in the form of "Relation between occupational environmental factors and genome of a male having infertility factors." 


\section{Study Design:}

Relevant data on the demographics and treatment history as well as the indications will be recorded (Figure 1). Counselling of all patients for research work will be done:

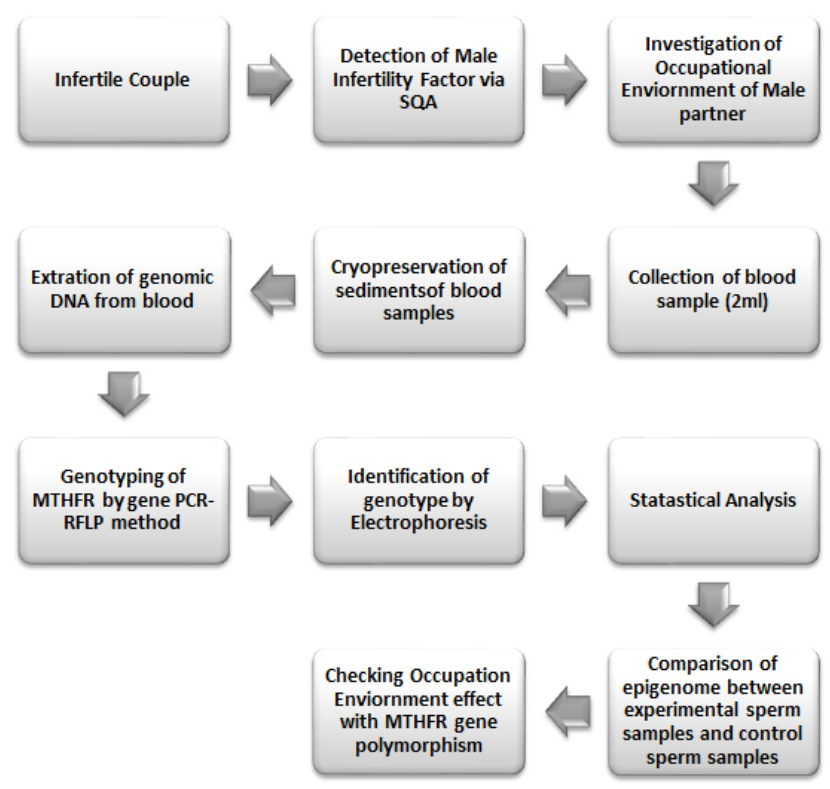

Figure 1: Study design based on demographics and treatment history.

\section{Epigenetic analysis}

DNA will be extracted from the blood of the patient and analysed for methylation status of genes responsible for spermatogenesis using PCR-RFLP followed by Agarose gel electrophoresis and visualisation by Gel Doc or UV Illuminator. Following genes will be analysed for DNA Methylation which may be responsible for male infertility (Figure 2).

- $\quad$ MTHFR Gene Polymorphism

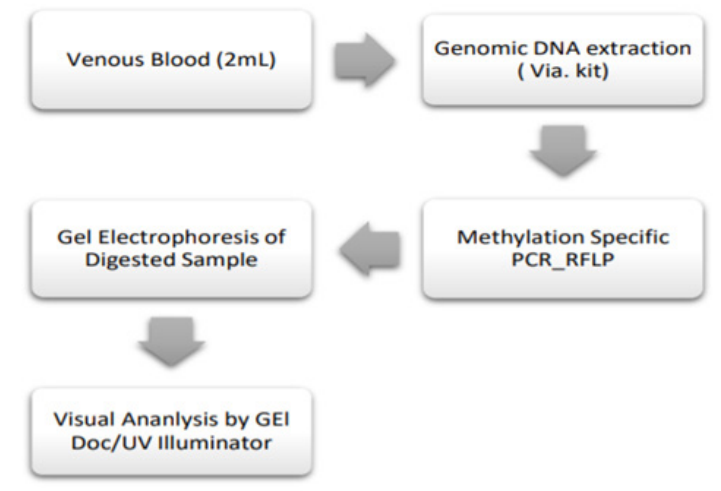

(Diagrammatic Representation Of Genetic Study Methodology)

Figure 2: Diagrammatic representation of genetic study methodology.

\section{Setting:}

Locations: TEST TUBE BABY CENTRE, AVBRH, Sawangi Meghe, Wardha.

Relevant Dates \& Including periods of recruitment: August 2019 - August 2021

\section{Participants:}

\section{Inclusion Criteria:}

Male having infertility factors (as the subject of study) and healthy male (as a control) attending WARDHA TEST TUBE BABY CENTRE, AVBRH

\section{Data sources/measurement:}

In case of availing effect of Occupational Environment on male infertility, variables in form of semen sample of male with abnormal semen profile are to be most expected to be included in the study will be "exposure to Heat, Telecommunication radiations and chemicals". Same variables will be subjected to be a subgroup constituting equal elements. Certain other variables will be included in the study only if the number of elements/samples of that group matches the set number of existing groups to the study sample for subsequent comparison with other affecting factors.

In the case of Epigenetic assessment of elements of groups, variables will be considered in the form of number bands of gene samples observed in complete electrophoresis run after being digested by the restriction enzyme. The elements of each group (Experimental samples) will be compared for digested band ratio with one with healthy semen profile having the same occupation environmental exposure (Control Sample).

After collection of data in both scenarios, a comparison of digested gene band ratio will be compared with intra groups of variables compiling different Occupation Environment to estimate the most relevant factor affecting epigenetic cause leading male infertility cause.

\section{Exclusion Criteria:}

- Patient having systemic organic disease, endocrine factors, reproductive tract disease will be excluded from the study.

- Patients not giving consent for research

- Patients having infections like HIV, HBsAg etc.

\section{Study size:}

Sample Size: 60 infertile males

$\mathrm{N}=\boldsymbol{k}^{2} * \mathrm{~N} * \mathrm{p}(1-\mathrm{p})$

$\mathrm{C}^{2}(\mathrm{~N}-1)+\aleph^{2} \mathrm{p}(1-\mathrm{p})$

Total population $=\mathrm{N}=60$ during 36 months 
$\aleph^{2}=$ Chi-square value for 1 degrees at some desired probability level.

This is 3.84 at $5 \%$ level of significance.

$$
\begin{aligned}
& \mathrm{P}=50 \% \text { proportion } \\
& \mathrm{Q}=100-\mathrm{p} \\
& =60 \\
& \mathrm{C}=\text { Confidence interval of the one choice }(95 \% \mathrm{CI}) \\
& =0.05 \\
& \mathrm{~N}=3.84 * 60 * 0.5 * 0.5 \\
& (0.05)^{2} * 24+3.84 *(0.5 * 0.5) \\
& =60
\end{aligned}
$$

\section{Expected Outcomes/Results}

Initially, at the stage of collection of data for this research work, enrollment of \pm 20 participants are expected quarterly (3 months) with prior Consent and Performa. Male participants with abnormal semen profile having systemic organic disease, endocrine factors, reproductive tract disease and having infections like HIV, HBsAg etc.; will not be included in the study due to sensitivity and severity of that particular case. Knowing to the geographical, physiological and working culture of subjected zone form which participants will be enrolled for the study, it is expected that; three variable groups (Heat; Telecommunication radiation and chemical) will be formed concerning the exposure of environmental occupation on fertility perspective. Eventually, the severity of epigenetic cause for male infertility is expected to see in participants with \pm 15 years the exposure of any one or a combination of the variables of occupational environment.

\section{DISCUSSION}

Taking geographical, physiological and working culture of the zone where the study is samples are collected into consideration, the factor for studying the occupational environment impact is kept limited to Heat; Telecommunication Radiation and Chemical exposure. Few of the studies on male infertility were reported. ${ }^{10-12}$ Evidence is also reflected in the global burden of disease study. ${ }^{13-15}$ Due to limitation of time and funds, the epigenetic study is limited till band ratio screening of after PCR-RFLP digestion of sample gene strand. In future, several other occupational environmental factors; Lifestyle; etc. can be studied to check its impact on male infertility and can also be compared to check its correlation with epigenetic factors and even same study can be made more precise by sequencing or NGS (Next Gen. Sequencing) of the DNA sample to check the exact methylation points.

\section{CONCLUSION}

Correlation of professional exposure to male infertility will become evident with this study.

\section{ACKNOWLEDGMENT}

Authors acknowledge the immense help received from the scholars whose articles are cited and included in references to this manuscript. The authors are also grateful to authors / editors / publishers of all those articles, journals, and books from which the literature for this article has been reviewed and discussed.

\section{Conflict of Interest: Nil}

\section{Source of Funding: Nil}

Ethical Approval: IEC, DMIMS, Wardha

\section{REFERENCES}

1. Stouffs K, Lissens W, Tournaye H, Van Steirteghem A, Liebaers I. The choice and outcome of the fertility treatment of 38 couples in whom the male partner has a Yq microdeletion. Hum Reprod 2005;20(7):1887-96.

2. Krausz C, Forti G. Clinical aspects of male infertility. In: McElreavey $\mathrm{K}(\mathrm{Ed})$ : The genetic basis of male infertility. Berlin: Springer-Verlage. 2000:1-21

3. Sinawat $\mathrm{S}$. The environmental impact on male fertility. Journal of the Medical Association of Thailand. Chotmaihet thangphaet 2000;83(8):880-5.

4. Poongothai J, Gopenath TS, Manonayaki S. Genetics of human male infertility. Singapore Med J 2009; 50(4)336-47.

5. Bird A. Perceptions of epigenetics. Nature 2007;447(7143):396.

6. Egger G, Liang G, Aparicio A, Jones PA. Epigenetics in human disease and prospects for epigenetic therapy. Nature 2004;429(6990):457-63.

7. Saunders PT, Turner JM, Ruggiu M, Taggart M, Burgoyne PS, Elliott D, et al. Absence of mDazl produces a final block on germ cell development at meiosis. Reproduction 2003;126(5):589-97.

8. Singh K, Singh SK, Sah R, Singh I, Raman R. Mutation C677T in the methylenetetrahydrofolate reductase gene is associated with male infertility in an Indian population 1. Int J Androl 2005;28(2):115-9.

9. Tüttelmann F, Rajpert-De Meyts E, Nieschlag E, Simoni M. Gene polymorphisms and male infertility-a meta-analysis and literature review. Reproduct Biomed 2007;15(6):643-58.

10. Kakade A, Padamwar M, Gode D, Mahakalkar C, Kamble A, Nagdive A. Clinical Study of the Effect of Varicocelectomy on Parameter of Semen Analysis of Infertile Men. J Crit Rev 2020;7(8):1116-9.

11. Singh BR, More A, Ambad RS, Bankar N, Ghogare AS. Comparative study of transferring frozen embryo with short culture vresus overnight culture and also assess prevalence rate of psychological distress amongs infertility patient. Int J Res Pharma Sci 2020;11(2):2489-92.

12. Varma A, Verma N, Acharya N, Nadkarni A. Study of Karyotyping and Y Chromosome Microdeletionscreening in Infertile Males with Azoospermia and Oligozoospermia Prior to Art. Int J Cur Res Rev 2202;12(16):84. 
13. James SL, Castle CD, Dingels ZV, Fox JT, Hamilton EB, Liu Z, et al. Estimating global injuries morbidity and mortality: methods and data used in the Global Burden of Disease 2017 study. Inj Prev 2020;26(1):i125-53.

14. Murray CJL, Abbafati C, Abbas KM, Abbasi M, Abbasi-Kangevari $\mathrm{M}$, Abd-Allah F, et al. Five insights from the Global Burden of Disease Study 2019. Lancet 2020;396(10258):1135-59.
15. Wang H, Abbas KM, Abbasifard M, Abbasi-Kangevari M, Abbastabar H, Abd-Allah F, et al. Global age-sex-specific fertility, mortality, healthy life expectancy (HALE), and population estimates in 204 countries and territories, 1950-2019: a comprehensive demographic analysis for the Global Burden of Disease Study 2019. Lancet 2020;396(10258):1160-203. 